\title{
Alpha 1 Acid Glycoprotein as a Marker for Diagnosis of Early-Onset Neonatal Sepsis in Full-term Neonates
}

\author{
Azza Ali Khalil ${ }^{1}$, Safaa Hamdy Ahmad ${ }^{1}$, Naglaa Ali KHalifa ${ }^{2}$, Gameel Hassan Mansor*1 \\ Departments of ${ }^{1}$ Pediatrics and ${ }^{2}$ Clinical Pathology, Faculty of Medicine, Zagazig University, Sharkia, Egypt \\ *Corresponding Author: Gameel Hassan Mansor, Mobile: (+20)01064381557, Email: drjamilhasan@ gmail.com
}

\begin{abstract}
Background: Neonatal sepsis is defined as a clinical syndrome of bacteremia with systemic signs and symptoms of infection in the first 4 weeks of life. Alpha-1 acid glycoprotein is one of the lipocalin family and members of acutephase protein; it appears to function in modulating the activity of the immune system during the acute phase reaction.

Objective: This study aimed to assess $\alpha-1$ AGP as a marker in the diagnosis of EOS.

Patients and Methods: This study was a prospective case-control study conducted on full-term neonates up to 7 days of life, admitted to the neonatal intensive care unit of Zagazig University Hospitals. The studied neonates were divided into 3 groups first confirmed cases (20) of early-onset sepsis, confirmed clinically and with a positive blood culture. Second suspected cases (20), with clinical features of sepsis and non-specific lab markers. Third group control (20), are apparently healthy term newborns, delivered in the Zagazig University Hospital. Alpha-1 acid glycoprotein was measured for all neonates.
\end{abstract}

Results: There was a statistically significant difference among the studied groups as regard alpha one acid glycoprotein. It is a good diagnostic marker detection of cases.

Conclusion: Alpha-1-acid glycoprotein appeared to be a useful marker for the early detection and diagnosis of earlyonset neonatal sepsis.

Keywords: Alpha 1 Acid Glycoprotein, Early Onset Neonatal Sepsis, Fullterm Neonates Diagnosis.

\section{INTRODUCTION}

A case definition for neonatal sepsis is lacking and neonatal sepsis is variably defined. However, specific criteria that classify sepsis into culture-proven, possible and probable sepsis have been developed using clinical and laboratory findings. Moreover, the term 'clinical sepsis' is commonly used by neonatologists and clinicians in the presence of negative blood culture, and clinical symptoms and signs of sepsis. However, this term also lacks consensus and no clear criteria exist for its use in research and clinical practice. Neonatal sepsis is classified by the time and onset of the disease into early and late-onset ${ }^{(\mathbf{1})}$.

Early-onset neonatal sepsis (EONS) is the one that occurs in the first 3 days of an infant's life and is often due to vertical transmission of organisms from the maternal genitourinary tract, while late-onset neonatal sepsis (LONS) is defined as sepsis occurring in infants older than 72 hours and is commonly due to horizontal transmission. However, the time limits for defining early and late-onset sepsis lack consensus too, and many authors extend the duration of EONS for up to 7 days following birth. Historically, blood culture is considered the "gold standard" test for the diagnosis of sepsis. However, the low yield of blood culture often leads to more reliance on clinical judgment in treating infants with suspected sepsis ${ }^{(\mathbf{1})}$.

When pathogenic bacteria gain access into the blood stream, they may cause overwhelming infection (septicemia) or may get predominantly localized to the lung (pneumonia) or the meninges (meningitis) ${ }^{(2)}$.

The World Health Organization (WHO) estimates that $45 \%$ of deaths in under-five years occur during their first month of life. Almost one million deaths occur on the day of birth and close to two million die in the first week of life. Incidence of neonatal sepsis varies from 1$4 / 1000$ live births in developed countries to $10-50 / 1000$ live births in developing countries. Incidence in Egypt was found to be $21.5 \%$ of neonates admitted to NICU (3). Similar studies in Egypt reported a higher rate around $33 \%$ among neonates admitted to $\operatorname{NICU}^{(4,5)}$.

Accurate and timely diagnosis of early-onset neonatal sepsis remains challenging to the clinicians and the laboratory ${ }^{(6)}$. Various strategies to reduce morbidity and mortality involve the use of clinical signs with hematological and serological markers ${ }^{(7)}$. Alpha-1 acid glycoprotein is one of the lipocalin family and members of acute-phase proteins, it appears to have a function in modulating the activity of the immune system during the acute phase reaction ${ }^{\left({ }^{(8)} \text {. }\right.}$

This study aimed to assess $\alpha-1$ AGP as a diagnostic biomarker in EOS in full-term.

\section{PATIENTS AND METHODS}

This study was a prospective case-control study conducted on full-term neonates up to 7 days of life, admitted to the neonatal intensive care unit of Zagazig University Hospitals.

The studied neonates were divided into 3 groups first confirmed cases (20) of early-onset sepsis, confirmed clinically and with a positive blood culture. Second suspected cases (20), with clinical features of sepsis and non-specific lab markers. Third group control (20), are apparently healthy term newborns, delivered in the Zagazig University Hospital. 
Inclusion criteria: All delivered full-term neonates, and with risk factors of developing EOS such as premature rupture of membrane and maternal urinary tract infection were included. Neonates with clinical presentation suggesting sepsis as temperature instability, shock, hypoperfusion, respiratory distress or apnea, bleeding, convulsions, skin mottling, and inability to take feed were included, and neonates with laboratory evidence of sepsis in the first 72 hours according to HSS (hematological sepsis score).

Exclusion criteria: All neonates with conditions that can affect $\alpha$-1AGP level other than sepsis such as neonatal birth trauma or congenital anomalies or given corticosteroids.

\section{All neonates who suspect to have sepsis were subjected to the following:}

1) Maternal history: Including maternal disease with pregnancy (diabetes mellitus, hypertension, and urinary tract infection). History of chorioamnionitis or premature rupture of membrane (PROM) and intrapartum fever.

2) Natal history: Mode of delivery, GA, sex, body weight, and Apgar score.

3) Physical examination of the baby.

4) Laboratory investigations :

\section{Blood cultures:}

Blood for culture was collected and dispensed with great care as indicated to avoid contaminating the specimen and culture medium. Wearing gloves, thoroughly disinfect the venepuncture site as follows:

- Using 70\% ethanol; cleanse an area about $50 \mathrm{~mm}$ in diameter and allow to air dry.

- Using 2\% tincture of iodine and a circular action, swab the area beginning at the point where the needle will enter the vein. Allow the iodine to dry on the skin for at least 1 minute. Using a sterile syringe, withdraw about $6 \mathrm{ml}$ of blood and inoculate it immediately in the blood culture bottle $(2 \mathrm{ml}$ for blood culture, $2 \mathrm{ml}$ for CBC and CRP, $2 \mathrm{ml}$ for Apo A1).

The foil cap of the blood culture bottle was held cut and then the rubber cap was wiped using an ethanol swab, then perforated with the syringe containing the collected blood. The top of the culture bottle was wiped again with an ethanol swab and the foil cap was replaced. The blood was mixed with the broth without delay. The bottles were labeled with the name, the number of the case, and the date of collection. The blood culture bottles were incubated at $37^{\circ} \mathrm{C}$. Subculture was done after the first-night incubation on Blood agar that was aerobically incubated at $37^{\circ} \mathrm{C}$ for 24 hours, MacConkey agar that was aerobically incubated at $37^{\circ} \mathrm{C}$ for 24 hours, and the plates were examined after the incubation period for growth. Negative blood culture bottles were checked every other day for evidence of microbial growth (hemolysis, turbidity, gas production, or presence of visible growth). If there is no evidence of microbial growth after 10 days of incubation, Gram stains and terminal subcultures were done before considering the culture as negative. +ve blood cultures were identified using Vitec 2 with subsequent Antibiotic sensitivity.

\section{Alpha one acid glycoprotein by ELISA Kit:}

Intended use: this kit is used to assay the alpha 1 acid glycoprotein ( $\alpha$ 1-AGP) in the sample of human serum, blood plasma, and other related tissue liquid. Test principle: the kit uses a double-antibody sandwich enzyme-linked immunosorbent assay (ELIZA) to assay the level of human $\alpha 1$-acid glycoprotein ( $\alpha$ 1-AGP) in samples. Add ( $\alpha$ 1-AGP) to the monoclonal antibodyenzyme well which is pre-coated with human $(\alpha 1$ AGP) monoclonal antibody, incubation; then add ( $\alpha$ 1-AGP ) antibodies labeled with biotin, and combined with streptavidin -HRP to form an immune complex; then carry out incubation and washing again to remove the uncombined enzyme. Then add chromogen solution $\mathrm{A}, \mathrm{B}$, the color of the liquid changes into blue, and the effect of acid, the color finally becomes yellow. The chroma of color and the concentration of the human substance ( $\alpha$ 1-AGP) of the sample were positively correlated.

\section{Ethical consent:}

Approval of the study was obtained from Zagazig University academic and ethical committee. Every neonatal guardian signed informed written consent for the acceptance of the operation. This work has been carried out following The Code of Ethics of the World Medical Association (Declaration of Helsinki) for studies involving humans.

\section{Statistical analysis}

The collected data were tabulated and analyzed using SPSS version 16 software (Spss Inc, Chicago, ILL Company). Categorical data were presented as numbers and percentages. Chi-square test $\left(\mathrm{X}^{2}\right)$, or Fisher's exact test (FET) were used to analyze categorical variables. Quantitative data were tested for normality using the Kolmogorov Smirnov test assuming normality at $\mathrm{P}>0.05$. Quantitative data were expressed as mean \pm standard deviation, median, and range. Student "t" test was used to analyze normally distributed variables among 2 independent groups, or Man Whitney $U$ test for nonparametric ones. ROC curve was used to detect cutoff values with optimum sensitivity and specificity in early diagnosis and prediction of diagnosis of sepsis. P-value $<0.05$ was considered significant.

\section{RESULTS}

There was no statistically significant difference between Confirmed neonatal sepsis, Suspected neonatal sepsis, and control group regarding age (days) and Sex (Table 1). 
There was a statistically significant difference among the studied groups as regard birth weight, APGAR score at 1 and 5 minutes. While there was no significant difference among the studied groups as regard multiple pregnancies, mode of delivery, and GA. There was a statistically significant difference between group I and group II as regard birth weight, APGAR score at 1 and $5 \mathrm{~min}$. There was a statistically significant difference between group I and group III as regards birth weight, APGAR score at 1 and 5 min. There was a significant difference between group II and group III only as regard birth weight (Table 2).

There was a statistically significant difference among the studied groups as regard PROM, maternal UTI, and hypertension. There was a statistically significant difference between group I and group II as regard PROM, maternal UTI, and hypertension. There was a statistically significant difference between groups
I and III as regard PROM, maternal UTI, and hypertension (Table 3).

There was a statistically significant difference among the studied groups as regard alpha one acid glycoprotein. There was a statistically significant difference between group I and group II as regard alpha one acid glycoprotein. There was a statistically significant difference between group I and group III as regard alpha one acid glycoprotein. There was a statistically significant difference between group II and group III as regard alpha one acid glycoprotein (Table 4). Receiver operating characteristic (ROC) curve of alpha one acid glycoprotein was conducted. Excellent AUC was found (AUC $=0.92)$. At the best cut-off value of (120), sensitivity was $95 \%$, specificity was $90 \%$, PPV was $90.5 \%$, NPV was $94.7 \%$, accuracy was $92.5 \%$ (Table 5).

Table (1): Comparison between Confirmed neonatal sepsis, Suspected neonatal sepsis, and control group regarding demographic data.

\begin{tabular}{|c|c|c|c|c|c|c|}
\hline & & & $\begin{array}{c}\text { Confirmed } \\
\text { neonatal sepsis } \\
\text { (group I) }\end{array}$ & $\begin{array}{c}\begin{array}{c}\text { Suspected } \\
\text { neonatal sepsis } \\
\text { (group II) }\end{array} \\
\end{array}$ & $\begin{array}{c}\text { control } \\
\text { (group III) }\end{array}$ & P-value \\
\hline age (days) & Mean & & $3.70 \pm 1.59$ & $\begin{array}{c}4.00 \pm \\
1.62\end{array}$ & $\begin{array}{l}4.05 \pm \\
1.39\end{array}$ & 0.740 \\
\hline \multirow{4}{*}{ Sex } & \multirow{2}{*}{ Female } & No. & 7 & 8 & 10 & \multirow[t]{4}{*}{0.619} \\
\hline & & $\%$ & $35.0 \%$ & $40.0 \%$ & $50.0 \%$ & \\
\hline & \multirow{2}{*}{ Male } & No. & 13 & 12 & 10 & \\
\hline & & $\%$ & $65.0 \%$ & $60.0 \%$ & $50.0 \%$ & \\
\hline
\end{tabular}

Table (2): Comparison of fetal risk factors among the studied groups.

\begin{tabular}{|c|c|c|c|c|c|c|c|}
\hline & & & $\begin{array}{c}\text { Confirmed } \\
\text { neonatal sepsis } \\
\text { (group I) }\end{array}$ & $\begin{array}{c}\text { Suspected } \\
\text { neonatal sepsis } \\
\text { (group II) }\end{array}$ & $\begin{array}{c}\text { control } \\
\text { (group } \\
\text { III) }\end{array}$ & $\begin{array}{c}P \text { - } \\
\text { value }\end{array}$ & LSD \\
\hline \multirow{2}{*}{$\begin{array}{l}\text { Multiple } \\
\text { pregnancy }\end{array}$} & \multirow[t]{2}{*}{ Yes } & No. & 18 & 18 & 19 & \multirow[t]{2}{*}{.804} & \\
\hline & & $\%$ & $90.0 \%$ & $90.0 \%$ & $95.0 \%$ & & \\
\hline \multirow{4}{*}{$\begin{array}{l}\text { Mode of } \\
\text { delivery }\end{array}$} & \multirow[t]{2}{*}{ CS } & No. & 7 & 9 & 4 & \multirow[t]{4}{*}{.241} & \\
\hline & & $\%$ & $35.0 \%$ & $45.0 \%$ & $20.0 \%$ & & \\
\hline & \multirow{2}{*}{$\begin{array}{l}\text { Normal } \\
\text { vaginal } \\
\text { delivery }\end{array}$} & No. & 13 & 11 & 16 & & \\
\hline & & $\%$ & $65.0 \%$ & $55.0 \%$ & $80.0 \%$ & & \\
\hline \multicolumn{2}{|c|}{ GA in weeks } & Mean \pm SD & $38.00 \pm 1.37$ & $37.45 \pm 1.27$ & $\begin{array}{c}38.25 \pm \\
1.44 \\
\end{array}$ & .176 & \\
\hline \multicolumn{2}{|c|}{ Birth weight (gm) } & Mean \pm SD & $\begin{array}{c}2573.00 \pm \\
568.48\end{array}$ & $\begin{array}{c}2851.00 \pm \\
137.68\end{array}$ & $\begin{array}{c}3114.00 \pm \\
154.15\end{array}$ & .000 & $\begin{array}{l}\mathrm{P} 1=.015 \\
\mathrm{P} 2=.000 \\
\mathrm{P} 3=.021\end{array}$ \\
\hline \multicolumn{2}{|c|}{ APGAR score at $1 \mathrm{~min}$} & Mean \pm SD & $5.70 \pm .801$ & $6.55 \pm .510$ & $\begin{array}{c}6.20 \pm \\
.767\end{array}$ & .001 & $\begin{array}{l}\mathrm{P} 1=.000 \\
\mathrm{P} 2=.029 \\
\mathrm{P} 3=.122\end{array}$ \\
\hline \multicolumn{2}{|c|}{ APGAR score at 5 min } & Mean \pm SD & $\begin{array}{c}6.90 \pm \\
.788\end{array}$ & $\begin{array}{c}8.35 \pm \\
.745\end{array}$ & $\begin{array}{c}8.50 \pm \\
.512\end{array}$ & .000 & $\begin{array}{l}\mathrm{P} 1=.000 \\
\mathrm{P} 2=.000 \\
\mathrm{P} 3=.496\end{array}$ \\
\hline
\end{tabular}

$\mathrm{P} 1$ = comparison between groups I, II. p2 = comparison between groups I, III.

p3 = comparison between groups II, III. 
Table (3): Comparison between Confirmed neonatal sepsis, Suspected neonatal sepsis, and control group regarding maternal risk factors.

\begin{tabular}{|c|c|c|c|c|c|c|c|}
\hline & & $\begin{array}{c}\text { Confirmed } \\
\text { neonatal } \\
\text { sepsis } \\
\text { (group I) } \\
\end{array}$ & $\begin{array}{c}\text { Suspected } \\
\text { neonatal } \\
\text { sepsis } \\
\text { (group II) }\end{array}$ & $\begin{array}{l}\text { Control } \\
\text { (group } \\
\text { III) }\end{array}$ & $\mathbf{X}^{2}$ & $\begin{array}{c}P \text { - } \\
\text { value }\end{array}$ & LSD \\
\hline \multirow[t]{2}{*}{ PROM } & No. & 13 & 4 & 0 & \multirow[t]{2}{*}{21.833} & \multirow[t]{2}{*}{.000} & $\mathrm{P} 1=0.010$ \\
\hline & $\%$ & $65.0 \%$ & $20.0 \%$ & $.0 \%$ & & & $\begin{array}{l}\mathrm{P} 2=0.000 \\
\mathrm{P} 3=0.106\end{array}$ \\
\hline \multirow[t]{2}{*}{ Maternal UTI } & No. & 9 & 1 & 0 & \multirow[t]{2}{*}{17.520} & \multirow[t]{2}{*}{.000} & $\mathrm{P} 1=0.010$ \\
\hline & $\%$ & $45.0 \%$ & $5.0 \%$ & $.0 \%$ & & & $\begin{array}{c}\mathrm{P} 2=0.001 \\
\mathrm{P} 3=1.00\end{array}$ \\
\hline \multirow[t]{2}{*}{ Diabetes } & No. & 13 & 7 & 6 & \multirow[t]{2}{*}{5.837} & \multirow[t]{2}{*}{.054} & $\mathrm{P} 1=0.113$ \\
\hline & $\%$ & $65.0 \%$ & $35.0 \%$ & $30.0 \%$ & & & $\begin{array}{l}\mathrm{P} 2=0.057 \\
\mathrm{P} 3=0.735\end{array}$ \\
\hline \multirow[t]{2}{*}{ Hypertension } & No. & 13 & 6 & 3 & \multirow[t]{2}{*}{11.340} & \multirow[t]{2}{*}{.003} & $\mathrm{P} 1=0.057$ \\
\hline & $\%$ & $65.0 \%$ & $30.0 \%$ & $15.0 \%$ & & & $\begin{array}{l}\mathrm{P} 2=0.003 \\
\mathrm{P} 3=0.448\end{array}$ \\
\hline
\end{tabular}

$\mathrm{P} 1$ = comparison between group I and group II.

P3 = comparison between group II and group III.

P2 =comparison between group I and group III.

Table (4): Comparison between confirmed and suspected neonatal sepsis and control group regarding alpha one acid glycoprotein.

\begin{tabular}{||l|c|c|c|c|c|c|c|}
\hline \multicolumn{2}{|l|}{} & $\begin{array}{c}\text { Confirmed } \\
\text { neonatal } \\
\text { sepsis } \\
\text { (group I) }\end{array}$ & $\begin{array}{c}\text { Suspected } \\
\text { neonatal } \\
\text { sepsis } \\
\text { (group II) }\end{array}$ & $\begin{array}{c}\text { Control } \\
\text { (group } \\
\text { III) }\end{array}$ & F-test & $\begin{array}{c}\text { P- } \\
\text { value }\end{array}$ & LSD \\
\hline $\begin{array}{l}\text { alpha one acid } \\
\text { glycoprotein } \\
(\boldsymbol{\mu M} / \mathbf{d I})\end{array}$ & $\begin{array}{c}\text { Mean } \pm \\
\text { SD }\end{array}$ & $\begin{array}{c}142.78 \pm \\
11.40\end{array}$ & $\begin{array}{c}107.73 \pm \\
6.37\end{array}$ & $\begin{array}{c}88.34 \pm \\
10.58\end{array}$ & 161.668 & 0.000 & $\begin{array}{c}\mathrm{P} 1=0.000 \\
\mathrm{P} 2=0.000 \\
\mathrm{P} 3=0.000\end{array}$ \\
\hline
\end{tabular}

$\mathrm{P} 1$ = comparison between group I and group II.

$\mathrm{P} 2$ = comparison between group I and group III.

$\mathrm{P} 3=$ comparison between group II and group III.

Table (5): Accuracy of alpha one acid glycoprotein in the diagnosis of cases.

\begin{tabular}{|l|c|}
\hline & Alpha one acid glycoprotein \\
\hline AUC & 0.92 \\
\hline Cut off & 120 \\
\hline Sensitivity (\%) & 95 \\
\hline Specificity (\%) & 90 \\
\hline PPV (\%) & 90.5 \\
\hline NPV (\%) & 94.7 \\
\hline Accuracy (\%) & 92.5 \\
\hline
\end{tabular}

AUC, the area under ROC curve; PPV, positive predictive value; NPV, negative predictive value.

\section{DISCUSSION}

This work showed a predominance of males (65\%) among patients with neonatal sepsis.

This goes with Higazi et al. ${ }^{(9)}$, in their study to evaluate the diagnostic and prognostic performances of urinary interleukin-18 (UIL-18) and serum amyloid A (SAA) in neonatal sepsis parallel to $\mathrm{C}$ - reactive protein. They found there is male predominance $(60 \%)$.

In the current study, there was no significant difference between the studied groups concerning gestational age $(\mathrm{p}>0.05)$.
This was in accordance with that reported by ElGendy et $\boldsymbol{a l} .{ }^{(10)}$ who found that there were no significant differences in gestational age in their study.

This study showed that there was a statistically significant difference between the studied groups regarding birth weight.

These results were in agreement with a study administered by Ocviyanti and Wahono (11) who found that the average birth weight of babies affected by neonatal sepsis was 1,420 grams, while for those without neonatal sepsis it had been 2,560 grams. 
In contradict with the present study, El-Gendy $\boldsymbol{e t}$ al. ${ }^{(10)}$ found that there were no significant differences in weight in their study.

This study showed that there was a statistically significant increase in alpha one acid glycoprotein among the confirmed and suspected neonatal sepsis groups than the control group.

This agrees also with Abdel Wahab et al. ${ }^{(12)}$ who found $\alpha-1$ AGP had a significantly high mean value $(122.8 \pm 66.1 \mathrm{mg} / \mathrm{dl})$ in the confirmed group compared to $(49.9 \pm 25.7 \mathrm{mg} / \mathrm{dl})$ in the suspected group and $(25.5 \pm 16.5 \mathrm{mg} / \mathrm{dl})$ in the controls.

Similarly, Nielsen et al. ${ }^{(13)}$ documented that increase the serum concentration of $\alpha$-AGP in sepsis than the control group.

$\alpha-1$ AGP is one of the acute phase proteins in humans, its serum concentration increase in response to tissue injury, inflammation, and infection. It is a useful marker for early detection of certain diseases as well as progression ${ }^{(14)}$.

This study showed that the receiver operating characteristic (ROC) curve of alpha one acid glycoprotein was conducted. Excellent AUC was found (AUC = 0.92). At the best cut-off value of (120), sensitivity was $95 \%$, specificity was $90 \%$, PPV was $90.5 \%$, NPV was $94.7 \%$, accuracy was $92.5 \%$.

This was in agreement with Abd Allah et al. ${ }^{(15)}$ who found ROC curve for serum alpha-1- acid glycoprotein level in the septic group showing an area under the curve (AUC) of 0.99.it showed that serum $\alpha$ 1 -acid glycoprotein was reliable to detect sepsis $(\mathrm{p}<0.01)$ and the cutoff value of serum alpha-1-acid glycoprotein to detect sepsis was $>136 \mathrm{ng} / \mathrm{dl}$ with sensitivity $93 \%$ and specificity of $91.3 \%$.

This comes in agreement with a study done by Ipek et al. ${ }^{(16)}$ which show similar results as the ROC curve for serum $\alpha$ - 1-acid glycoprotein level was constructed showing an area under the curve (AUC) 0.922 and cut off value to detect sepsis was> $134 \mathrm{ng} / \mathrm{dl}$, yielded a sensitivity of $89 \%$, specificity of $91 \%$.

\section{CONCLUSION}

Alpha-1-acid glycoprotein appeared to be a useful marker for the early detection and diagnosis of earlyonset neonatal sepsis.

\section{Financial support and sponsorship: Nil. Conflict of interest: Nil.}

\section{REFERENCES}

1. Braima O, Ali M, Abdulla E (2021): Bacteriological profile and antibiotic resistance in newborn infants with possible community-acquired neonatal sepsis in Khartoum State, Sudan. Sudanese Journal of
Paediatrics, 21(1): 13-22.

2. Sheng-Yuan H, Yun-Ru L, Chia-Te K et al. (2019): 1Acid Glycoprotein Concentration as an Outcome Predictor in Adult Patients with Sepsis. BioMed Research International, 19: 1-9.

3. Salama K, Gad A, El Tatawy S (2021): Sepsis profile and outcome of preterm neonates admitted to neonatal intensive care unit of Cairo University Hospital. Egypt Pediatric Association Gaz., 69: 8-12.

4. Mohsen L, Ramy N, Saied D et al. (2017): Emerging antimicrobial resistance in early and late-onset neonatal sepsis. Antimicrob Resist Infect Control, 6:1-6.

5. Awad H, Mohamed M, Badran $N$ et al. (2016) Multidrug-resistant organisms in neonatal sepsis in two tertiary neonatal ICUs, Egypt. J Egypt Public Health Assoc., 91:31-38.

6. Tam I, Bendel C (2017): Diagnostics for neonatal sepsis: Current approaches and future directions. Pediatric Research, 4: 574-583.

7. Brown J, Meader N, Cleminson J et al. (2019): Creactive protein for diagnosing late-onset infection in newborn infants.

https://pubmed.ncbi.nlm.nih.gov/30640979/

8. Connelly M, Otvos J, Shalaurova I et al. (2017): GlycA, a novel biomarker of systemic inflammation and cardiovascular disease risk. J Transl Med., 15: 219-223.

9. Higazi A, Mahrous D, Sayed S et al. (2016) Assessment of Urinary Interleukin-18 and Serum Amyloid A Efficacies against C-Reactive Protein in Diagnosis and Follow-up of Neonatal Sepsis. J Clin Cell Immunol., 7:446-52.

10. El-Gendy F, El-Lahony D, Midan D et al. (2018): Diagnostic value of apolipoprotein A1 in neonatal sepsis. Menoufia Med J., 31(3):1011-1017.

11. Ocviyanti D, Wahono W (2018): Risk Factors for Neonatal Sepsis in Pregnant Women with Premature Rupture of the Membrane. Journal of Pregnancy, 18: 16.

12. Abdel Wahab A, Elsharkawy $\mathrm{S}$, AbdAllah $\mathrm{N}$ et al. (2016): Alpha 1 acid glycoprotein as a marker for diagnosis of early-onset neonatal sepsis in full-term neonates. J Am Sci., 12(7):139-144.

13. Nielsen S, Grofte $T$, Tygstrup $\mathrm{N}$ et al. (2006): Synthesis of acute-phase proteins in rats with cirrhosis exposed to lipopolysaccharide. Comp Hepatol., 5:3-7.

14. Tesseromatis C, Alevizou A, Tigka E et al. (2011): Acute phase proteins: alpha 1 acid glycoprotein, regulation, and functions of acute-phase proteins. IntechOpen Book Series. https://www.intechopen.com/chapters/21455

15. Abd Allah M, Ahmady Awad A, Mohammed A et al. (2017): The predictive value of alpha 1 acid glycoprotein in the diagnosis of neonatal sepsis. AlAzhar Journal of Pediatrics, 20(2): 1777-1790.

16. Ipek I, Mehmet S, Bozaykut A (2010): Alpha one acid glycoprotein in early diagnosis of neonatal sepsis. $\mathbf{J}$ Matern Fetal Neonatal Med., 23 (7): 617-621. 